\title{
New Material of the Earliest Hominid from the Upper Miocene of Chad
}

\section{Citation}

Brunet, Michel, Franck Guy, David Pilbeam, Daniel E. Lieberman, Andossa Likius, Hassane T. Mackaye, Marcia S. Ponce de Leon, Christoph P. E. Zollikofer, and Patrick Vignaud. 2005. New material of the earliest hominid from the Upper Miocene of Chad. Nature 434: 752-755.

\section{Published Version}

doi:10.1038/nature03392

\section{Permanent link}

http://nrs.harvard.edu/urn-3:HUL.InstRepos:3716603

\section{Terms of Use}

This article was downloaded from Harvard University's DASH repository, and is made available under the terms and conditions applicable to Other Posted Material, as set forth at http:// nrs.harvard.edu/urn-3:HUL.InstRepos:dash.current.terms-of-use\#LAA

\section{Share Your Story}

The Harvard community has made this article openly available.

Please share how this access benefits you. Submit a story.

\section{Accessibility}




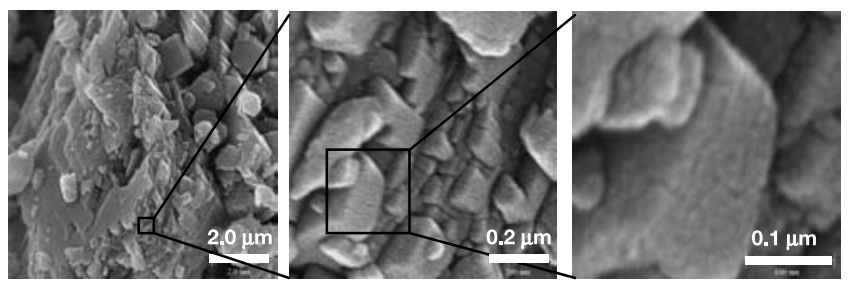

Figure 4 Scanning electron microscope images of untreated gouge from San Andreas gouge, with an order-of-magnitude resolution increase from left to right. The gouge samples were mounted onto colloidal graphite coating covering upper portions of platinum trays, and sputter-coated with gold-palladium under vacuum. Note the particles of $0.02-0.05 \mu \mathrm{m}$ in the middle and right frames.

event. In such a case, the observed gouge zone 70-100 m wide was formed by 7,000-10,000 earthquakes, which is in agreement with estimates of recurrence intervals. Although the present observations on gouge energetics are in accord with some studies ${ }^{30}$, they contradict common thought that gouge surface energy is a negligible component of earthquake energy balance ${ }^{3,9}$. If our conclusions are valid in general, they could explain, for example, the heat flow anomaly of the San Andreas fault system ${ }^{6}$.

\section{Methods}

We employ a Beckman Coulter LS230 laser diffraction particle size analyser. Its 750-nm laser source and proprietary polarization intensity differential scattering (PIDS) technology provide detection limits of $0.04-2,000 \mu \mathrm{m}$. Spectrometry by laser diffraction does not discern between primary particles and agglomerates and is therefore sensitive to the degree of agglomeration inside the analyser ${ }^{14,17}$. Disaggregation is a time-dependent process that can occur over the course of days in silicate mineral suspensions ${ }^{17}$. Accordingly, gouge PSD measurements lasting up to $190 \mathrm{~h}$ were taken, during which progressive disaggregation could be discerned (Figs 2,3). Initial sonication accelerated disaggregation but had no noticeable influence on the final PSD. Ultrafine particles might reagglomerate during the analysis ${ }^{14}$, as indicated by the increased scatter in surface area at long times (Fig. 3b). Power-law disaggregation (Fig. 3) and recurring agglomeration/ disaggregation during analysis indicates that PSD and surface area results are conservative estimates of primary gouge particle size and area produced by the seismic slip. Ultrafine particles could also have been lost as a result of Ostwald ripening and volatilization during sampling and handling.

The collected gouge samples were sealed at the site and stored in plastic bags. For the PSD measurements, tens of micrograms of sample were added to $25 \mathrm{ml}$ of an aqueous surfactant solution (usually $1 \%$ analytical reagent grade sodium metaphosphate prepared with doubly distilled water) or methanol and then subjected for $30 \mathrm{~min}$ to a low-energy sonic bath. After an additional $30 \mathrm{~min}$ this slurry was added to the laser analyser containing $125 \mathrm{ml}$ of the same solution. Measurements of the diffraction spectrum were performed with continuous circulation inside the analyser, and PIDS was used in all reported runs. Spectral analysis was performed with proprietary software using the Mie scattering mode ${ }^{14}$, with constants for the complex refractive index plus wavelength dependence for quartz ${ }^{14}$ and an absorption coefficient of 0.01 .

Received 4 December 2004; accepted 28 January 2005; doi:10.1038/nature03433.

. Sammis, C. G., Osborne, R. H., Anderson, J. L., Banerdt, M. \& White, P. Self-similar cataclasis in the formation of fault gouge. Pure Appl. Geophys. 124, 53-78 (1986).

2. Marone, C. \& Scholz, C. Particle-size distribution and microstructures within simulated fault gouge. J. Struct. Geol. 11, 799-814 (1989).

3. Scholz, C. H. The Mechanics of Earthquakes and Faulting (Cambridge Univ. Press, London, 2002).

4. Dor, O., Reches, Z. \& van Aswagen, G. in Rockburst and Seismicity in Mines Vol. 5 (eds van Aswegen, G., Durrheim, R. J. \& Ortlepp, W. D.) 109-112 (South African Inst. of Mining and Metallurgy, Johannesburg, 2001).

5. Chester, F. M., Evans, J. P. \& Biegel, R. L. Internal structure and weakening mechanisms of the SanAndreas Fault. J. Geophys. Res. Solid Earth 98, 771-786 (1993).

6. Zoback, M. D., Hickman, S. \& Ellsworth, W. San Andreas Fault observatory at depth. 〈http:// www.icdp.gfzpotsdam.de/html/sites/sanandreas/objectives/proposal.html (2002).

7. Ben-Zion, Y. \& Sammis, C. G. Characterization of fault zones. Pure Appl. Geophys. 160, 677-715 (2003).

8. Sleep, N. H. \& Blanpied, M. L. Creep, compaction, and the weak rheology of major faults. Nature 359, 687-692 (1992).

9. Olgaard, D. \& Brace, W. The microstructure of gouge from a mining-induced seismic shear zone. Int. J. Rock Mech. Mining Sci. 20, 11-19 (1983).

10. Steacy, S. J. \& Sammis, C. G. An automaton for fractal patterns of fragmentation. Nature 353, 250-252 (1991).

11. An, L. J. \& Sammis, C. G. Particle-size distribution of cataclastic fault materials from southern California-a 3-d study. Pure Appl. Geophys. 143, 203-227 (1994).

12. Kanamori, H. Mechanics of earthquakes. Annu. Rev. Earth Planet. Sci. 22, 207-237 (1994).

13. Brune, J. N. Fault-normal dynamic unloading and loading: an explanation for 'nongouge' rock powder and lack of fault-parallel shear bands along the San Andreas Fault. Eos 8, 47 (2001).

14. Xu, R. Particle Characterization: Light Scattering Methods (Kluwer Academic, Dordrecht, 2000).
15. Gregg, S. J. \& Sing, K. S. W. Adsorption, Surface Area and Porosity (Academic, London, 1982).

16. Dewers, T. A., Wilson, B. \& Reches, Z. Scaling particle size in fault gouge: Variable fractal dimension or non-fractal distribution? Eos 84, NG12C-06 (2003)

17. Franco, F., Perez-Maqueda, L. A. \& Perez-Rodriguez, J. L. The effect of ultrasound on the particle size and structural disorder of a well-ordered kaolinite. J. Colloid Interface Sci. 274, 107-117 (2004).

18. Evans, J. P. \& Chester, F. M. Fluid-rock interaction in faults of the San-Andreas System-Inferences from San-Gabriel fault rock geochemistry and microstructures. J. Geophys. Res. 100, 13007-13020 (1995)

19. Wilson, B. Meso- and Micro-structural Analysis of the San Andreas Fault at Tejon Pass, California. Thesis, Univ. Oklahoma, Norman (2004).

20. Smith, B. \& Dandwell, D. Coulomb stress accumulation along the San Andreas Fault system. J. Geophys. Res. 108, 2296 (2003).

21. McGarr, A., Spottiswoode, S. M., Gay, N. C. \& Ortlepp, W. D. Observations relevant to seismic driving stress, stress drop, and efficiency. J. Geophys. Res. 84, 2251-2261 (1978).

22. Ogasawara, H., Yanagidani, Y. \& Ando, M. (eds) Seismogenic Process Monitoring (Balkema, Rotterdam, 2002).

23. Ortlepp, W. D. Rock Fracture and Rockbursts (South Africa Institute of Mining and Metallurgy, Monograph series M9, 1997).

24. Hochella, M. F. Jr \& Banfield, J. F. in Chemical Weathering Rates of Silicate Minerals (eds White, A. F. \& Brantley, S. L.) 353-406 (Mineralogical Society of America, Washington DC, 1995).

25. Poliakov, A. N. B., Dmowska, R. \& Rice, J. R. Dynamic shear rupture interactions with fault bends and off-axis secondary faulting. J. Geophys. Res. 107, 2295 (2002).

26. Li, V. C. in Fracture Mechanics of Rocks (ed. Atkinson, B. K.) 351-428 (Academic, London, 1987).

27. Yund, R. A., Blanpied, M. L., Tullis, T. E. \& Weeks, J. D. Amorphous material in high strain experimental fault gouges. J. Geophys. Res. 95, 15589-15602 (1990).

28. Reches, Z. \& Dewers, T. A. Gouge formation by dynamic pulverization during earthquakes. Earth Planet. Sci. Lett. (submitted).

29. Grady, D. E. \& Kipp, D. E. Geometric statistics and dynamic fragmentation. J. Appl. Phys. 58, 1210-1222 (1985).

30. Reches, Z. Mechanisms of slip nucleation during earthquakes. Earth Planet. Sci. Lett. 170, 475-486 (1999).

Acknowledgements We thank the US National Science Foundation and the Southern California Earthquake Center for supporting this research.

Authors' contributions All authors contributed equally to this work.

Competing interests statement The authors declare that they have no competing financial interests.

Correspondence and requests for materials should be addressed to Z.R. (reches@.ou.edu).

\section{New material of the earliest hominid from the Upper Miocene of Chad}

\section{Michel Brunet ${ }^{1}$, Franck Guy ${ }^{1,2}$, David Pilbeam ${ }^{2}$, Daniel E. Lieberman ${ }^{2}$, Andossa Likius ${ }^{3}$, Hassane T. Mackaye ${ }^{3}$, Marcia S. Ponce de León ${ }^{4}$, Christoph P. E. Zollikofer ${ }^{4}$ \& Patrick Vignaud}

${ }^{1}$ Laboratoire de Géobiologie, Biochronologie et Paléontologie Humaine, CNRS UMR 6046, Faculté des Sciences, Université de Poitiers, 40 Avenue du Recteur Pineau, 86022 Poitiers Cedex, France

${ }^{2}$ Peabody Museum, Harvard University, 11 Divinity Avenue, Cambridge, Massachusetts 02138, USA

${ }^{3}$ Université de N'Djamena, BP 1117, N'Djamena, Tchad

${ }^{4}$ Anthropologisches Institut/MultiMedia Laboratorium, Universität

Zürich-Irchel, Winterthurerstrasse 190, 8057 Zürich, Switzerland

Discoveries in Chad by the Mission Paléoanthropologique Franco-Tchadienne have substantially changed our understanding of early human evolution in Africa ${ }^{1-3}$. In particular, the TM 266 locality in the Toros-Menalla fossiliferous area yielded a nearly complete cranium (TM 266-01-60-1), a mandible, and several isolated teeth assigned to Sahelanthropus tchadensis ${ }^{3}$ and biochronologically dated to the late Miocene epoch (about 7 million years ago). Despite the relative completeness of the TM 266 cranium, there has been some controversy about its morphology and its status in the hominid clade ${ }^{4,5}$. Here we describe new dental and mandibular specimens from three Toros-Menalla (Chad) fossiliferous localities (TM 247, TM 266 and TM 292) of 
the same age ${ }^{6}$. This new material, including a lower canine consistent with a non-honing $\mathrm{C} / \mathrm{P}_{3}$ complex, post-canine teeth with primitive root morphology and intermediate radial enamel thickness, is attributed to $S$. tchadensis. It expands the hypodigm of the species and provides additional anatomical characters that confirm the morphological differences between $S$. tchadensis and African apes. $S$. tchadensis presents several key derived features consistent with its position in the hominid clade close to the last common ancestor of chimpanzees and humans.

The upper Miocene vertebrate localities from the Toros-Menalla fossiliferous area discovered by the Mission Paléoanthropologique Franco-Tchadienne in the Mega-Chad basin, are north of the 16th parallel, $150 \mathrm{~km}$ west of the Koro-Toro australopithecine localities ${ }^{1,2,7}$. The faunal assemblage from TM 266 is found in the Anthracotheriid Unit, so named because it contains a very common, large anthracotheriid, Libycosaurus petrochii ${ }^{6}$. The mammalian fauna from the Anthracotheriid Unit, which includes a primitive suid, Nyanzachoerus syrticus, and a primitive loxodont elephant, contains more primitive taxa than the Lukeino fauna (Kenya, dating from $6 \mathrm{Myr}$ ago $)^{8}$ and is more similar to the fauna from the lower Nawata Formation of Lothagam (Kenya, 6.5-7.4 Myr ago) ${ }^{9}$. The Anthracotheriid Unit assemblage indicates a mosaic of landscapes ${ }^{6}$ probably resembling that of the present-day Okavango Delta (Botswana). Previous collecting in TM 266 uncovered a cranium, TM 266-01-60-1, as well as two mandibular fragments and several isolated teeth assigned to Sahelanthropus tchadensis ${ }^{3}$. Because of the age of this earliest hominid taxon (the term hominid is used here for convenience to denote all taxa that are closer to humans than chimpanzees, and does not connote any taxonomic scheme ${ }^{3}$; similarly, australopithecine is used as a generic term sensu lato to refer to all Pliocene hominid taxa that do not belong to the genera Ardipithecus and Homo), it is important to evaluate and expand the hypodigm to test hypotheses about its systematic relationships. Additional information that expands the Sahelanthropus tchadensis hypodigm comes from recent discoveries of new hominid material from TM 266 and from two new sites, TM 247 and TM 292, also in the Anthracotheriid Unit. These three sites are within a small area $\left(0.73 \mathrm{~km}^{2}\right)$. The new specimens (Table 1$)$ consist of two lower jaws (Figs 1,2 ) and the crown of a right $\mathrm{P}^{3}$ (Fig. 3 ).

TM 292-02-01 (Fig. 1) is a partial mandible fragment lacking the left and right corpus posterior to $\mathrm{M}_{2}$. The cortical bone is well preserved except in the antero-medial lower part of the symphyseal region, and in the alveolar process in the region of the incisors. The left $\mathrm{I}_{2}, \mathrm{C}_{1}, \mathrm{M}_{1}$ and $\mathrm{M}_{2}$ roots and right $\mathrm{I}_{1}-\mathrm{I}_{2}, \mathrm{P}_{3}$ and $\mathrm{M}_{1}-\mathrm{M}_{2}$ roots are preserved. The crowns of the left $M_{1}, M_{2}$ and the right $M_{1}$ are partly preserved, and the crown of the left canine is well preserved (Fig. 1g, h). TM 247-01-02 (Fig. 2) is a fragmentary right mandibular corpus. All the roots are well preserved; the crowns of $\mathrm{P}_{3}-\mathrm{M}_{1}$ are partly preserved but are missing in $\mathrm{M}_{2}-\mathrm{M}_{3}$. The corpus of the TM 292-02-01 fragment is more gracile (maximum corpus breadth at $\mathrm{M}_{1}$, perpendicular to corpus height, is $14.5 \mathrm{~mm}$ ) than that of the previously discovered TM 266-02-154-1 specimen ${ }^{3}$ (maximum corpus breadth at $\mathrm{M}_{1}$ is $20.0 \mathrm{~mm}$ ) as well as the newly discovered TM 247-01-02 (corpus breadth at $\mathrm{M}_{1}$ is $16.1 \mathrm{~mm}$ ), although this is a minimum estimate because the cortical bone surface has been eroded on the buccal side of the corpus. TM 292-02-01 and TM 247-01-02 each have a single, large mental foramen located at mid-corpus below $\mathrm{P}_{4}$. The anterior margin of the symphysis in

\begin{tabular}{|c|c|c|c|}
\hline \multicolumn{4}{|c|}{ Table 1 New specimens of Sahelanthropus tchadensis } \\
\hline Specimen number & Collected & Element & Discoverer \\
\hline TM 292-02-01 (Fig. 1) & 2002 & Mandibular fragment & MPFT \\
\hline TM 247-01-02 (Fig. 2) & 2001 & Right mandibular corpus fragment & MPFT \\
\hline TM 266-01-462 (Fig. 3) & 2001 & Right $P^{3}$ & MPFT \\
\hline
\end{tabular}

MPFT, Mission Paléoanthropologique Franco-Tchadienne.
TM 292-02-01 is vertical (Fig. 1c, d) with the rather damaged inferior part sloping posteriorly. The planum alveolare of the symphysis is about $45^{\circ}$ relative to the alveolar plane of the corpus. The inferior and superior transverse tori are weakly developed (superior is larger), and delimit a shallow genioglossal fossa with a large genioglossal foramen.

Among the mandibular teeth, only the lower left canine and $\mathrm{P}_{4}$ of TM 292-02-01 (Fig. 1e, g) are sufficiently well preserved to be described in detail. The canine crown, which is small with an asymmetrical outline in occlusal view at the cervix level (maximum mesiodistal length is $10.0 \mathrm{~mm}$, and buccolingual width is $8.5 \mathrm{~mm}$ ), is broken apically and worn distally. The wear pattern of the lower canine indicates that occlusion of the upper canine was solely against the large distal tubercle that projects lingually. This pattern of occlusion is clearly marked by a grooved wear strip on the distal
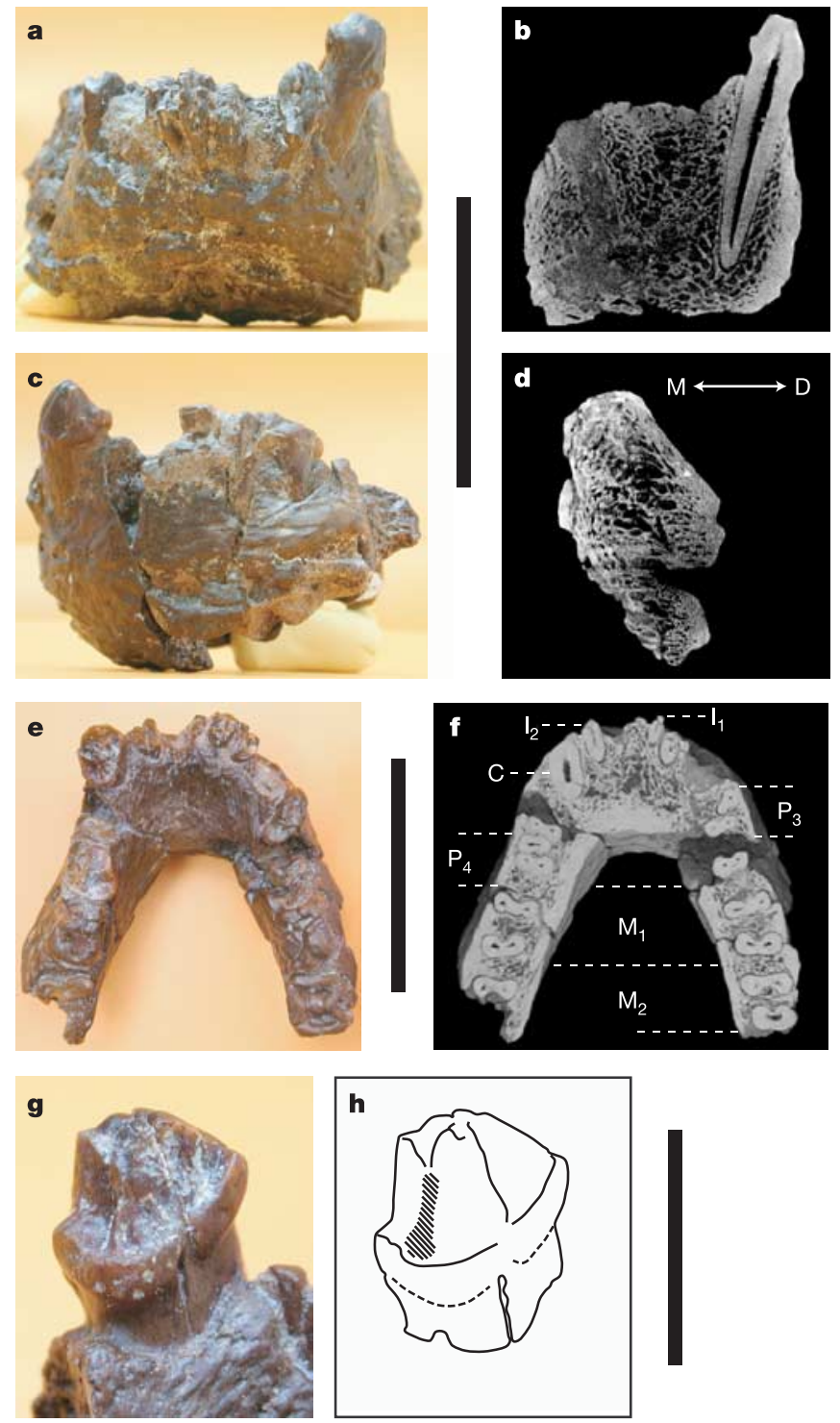

Figure 1 Lower jaw (TM 292-02-01) assigned to Sahelanthropus tchadensis. a, Frontal view. b, Left canine posterior coronal computed tomography (CT) scan (flipped horizontally) (scanner, University Museum, Tokyo, Japan). c, Left buccal view. d, Symphysis midsagittal CT scan (M, mesial; D, distal) (scanner, University Museum, Tokyo, Japan). e, Occlusal view. f, Three-dimensional reconstruction with axial CT scan; root pattern shown is taken just below the cervix (synchrotron, ESRF, Grenoble, France). $\mathbf{g}, \mathbf{h}$, Left canine disto-lingual view $(\mathbf{g})$ and drawing $(\mathbf{h})$ showing the location of the distal wear strip and indentation. Scale bar, $4 \mathrm{~cm}(\mathbf{a}-\mathbf{f}) ; 1 \mathrm{~cm}(\mathbf{g}, \mathbf{h})$. 


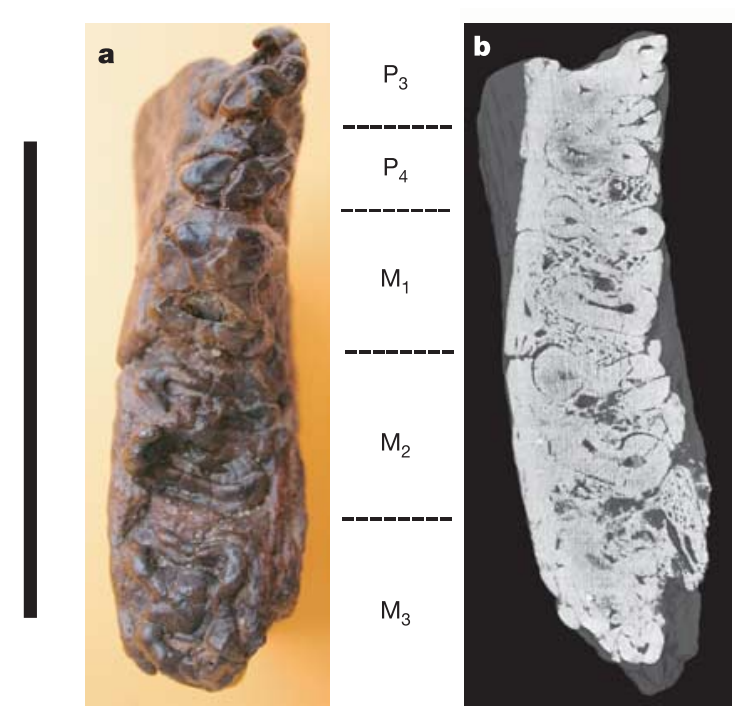

Figure 2 Right lower jaw (TM 247-01-02) assigned to Sahelanthropus tchadensis. a, Occlusal view. b, Three-dimensional reconstruction with axial computed tomography scan, root pattern shown is taken just below the cervix (synchrotron, ESRF, Grenoble, France). Scale bar, $4 \mathrm{~cm}$.

enamel surface that terminates in an indentation on the occlusal surface of the distal shelf-like tubercle (Fig. 1g, h). TM 292-02-01 is therefore consistent with the absence of a functional $\mathrm{C} / \mathrm{P}_{3}$ honing complex in S. tchadensis ${ }^{3}$. The crown of the canine is short, yet its root is surprisingly long (Fig. 1b). Both the mesial and distal crown shoulders (Fig. 1g, h) are very low relative to the cervix. In contrast to the configuration in Ardipithecus $k a d a b b a^{10,11}$ (Fig. 1b), the mesial shoulder is only slightly more apical than the distal shoulder. A distinct marginal ridge is present on the mesiolingual surface.

The subrectangular $\mathrm{P}_{4}$ of TM 292-02-01 has a maximum mesiodistal length of $8.0 \mathrm{~mm}$, with a distolingually well-developed talonid; the elongated partly preserved trigonid has a distinct distally positioned metaconid (Fig. 1e).

TM 266-01-462 (Fig. 3) is a right $\mathrm{P}^{3}$ lacking roots and a portion of the distal intercuspal crown. Dimensions of the $\mathrm{P}^{3}$ are $13.0 \mathrm{~mm}$ (buccolingual) and about $7.3 \mathrm{~mm}$ (minimum mesiodistal at paracone). The occlusal crown outline is oval with a slight concavity on its mesial surface below the marginal ridge. The mesial enamel surface shows a well-delimited interproximal canine wear facet below the mesial marginal ridge, confirming the lack of a diastema between $\mathrm{C}_{1}$ and $\mathrm{P}_{3}$. The mesial marginal ridge is above mid-crown level. In addition, the TM 266-01-462 premolar is bicuspid with a tall, conical paracone, and a smaller, lower protocone that is more mesially located than the paracone. Both cusps are slightly worn, with the tip of the paracone showing a small area of dentine exposure. The $\mathrm{P}^{3}$ presents a mesio-cervical enamel extension on the steeply sloping buccal surface. The small anterior fovea is mesial to the transverse crest of the paracone and bordered by a moderately thick mesial marginal ridge that slopes downwards buccally. The paracone has a prominent, rounded transverse crest extending slightly mesially to the median groove between the two cusps. The mesially facing triangular portion of the occlusal surface present in African apes and Ardipithecus ramidus is absent ${ }^{12}$.

The maximum radial enamel thickness measured from micro computed tomography scans of the $\mathrm{P}^{3}$ (TM 266-01-462, protocone and paracone), upper right $\mathrm{M}^{2}$ and $\mathrm{M}^{3}$ (TM 266-01-60-1, paracone, protocone and hypocone) and the right $\mathrm{P}_{4}$ (TM 266-02-154-1, protoconid) ranges from 1.2 to $1.9 \mathrm{~mm}$. The lower buccal and upper lingual cusps tend to have thicker enamel $(1.4-1.9 \mathrm{~mm})$ than the lower lingual and upper buccal cusps $(1.2-1.6 \mathrm{~mm})$. The postcanine
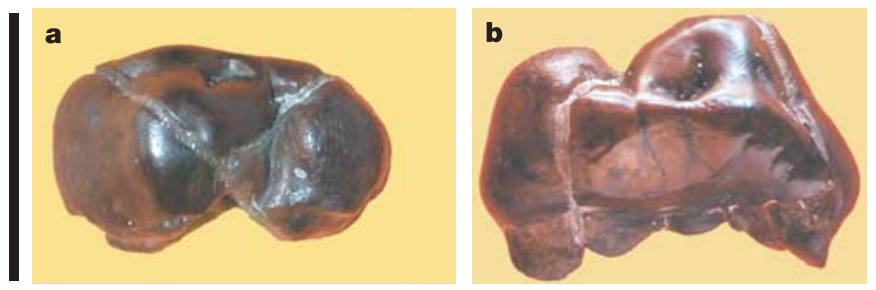

Figure 3 Right upper $\mathrm{P}^{3}$ (TM 266-01-462) assigned to Sahelanthropus tchadensis. a, Occlusal view. b, Mesial view. Scale bar, $1 \mathrm{~cm}$.

cuspal enamel thickness in these $S$. tchadensis specimens is therefore intermediate between published values for chimpanzees and australopithecines ${ }^{12}$.

The new material presented here is important for several reasons. First, the fossils add substantially to the holotype cranium, TM 26601-60-1, which is remarkable in its completeness and preservation. The $S$. tchadensis hypodigm now includes a minimum of six individuals (a maximum of nine) from three sites in a small area of the Anthracotheriid Unit. Second, these new fossils now permit a more complete and reliable understanding of this earliest known hominid taxon. S. tchadensis shares major derived features with other recognized hominids that are consistent with its position in the hominid clade, close to the last common ancestor of chimpanzees and humans. In the dentition these anatomical characters are a non-honing $\mathrm{C} / \mathrm{P}_{3}$ complex; no diastema between $\mathrm{C}$ and $\mathrm{P}_{3}$; a vertical symphysis with weak transverse tori; canines with a small crown and long root, a lower canine crown with a large distal tubercule, both shoulders being very low; an upper $\mathrm{P}^{3}$ with a steeply sloping buccal surface; postcanine teeth with maximum radial enamel thickness intermediate between chimpanzees and australopithecines; and bulbous, slightly crenulated postcanine occlusal morphology. All the hominid mandibular premolar specimens from Toros-Menalla have the same root pattern, with two roots and three separate pulp canals in each premolar (one mesial and two distal) retaining the presumed primitive condition for the Pan/Homo clade ${ }^{13}$ (Figs $1 \mathrm{f}$ and 2b).

The anatomical characters of the new material of S. tchadensis, such as a lower canine crown with a distinct mesial marginal ridge and a distal grooved wear strip ending on a large distal tubercle (a feature consistent with the absence of a honing $\mathrm{C} / \mathrm{P}_{3}$ complex), confirm the morphological differences of the Chadian species from African apes, and its morphological affinities with the hominid clade. Although the new fossils provide valuable data, the nearly complete cranium TM 266-01-60-1 remains a key specimen for S. tchadensis that is older than any other Late Upper Miocene hominid so far known ${ }^{10,11,14}$. Identifiable derived features of S. tchadensis $^{3}$ are a face with an anteroposteriorly short premaxilla, an anteriorly positioned foramen magnum linked to a short basioccipital and a sub-horizontal nuchal plane, a downward lipping of the nuchal crest, and a non-honing $\mathrm{C} / \mathrm{P}_{3}$ complex. Post-mortem plastic deformation of the TM 266 cranium has precluded further detailed analysis ${ }^{4}$. However, a virtual threedimensional reconstruction of the TM 266 cranium (presented in ref. 15) provides additional morphological information for the more precise evaluation of its systematic position with respect to the extant great apes and to other known hominid taxa, and for testing hypotheses about key aspects of its behaviour, particularly its mode of locomotion.

Received 17 September 2004; accepted 26 January 2005; doi:10.1038/nature03392.

\footnotetext{
1. Brunet, M. et al. The first Australopithecine 2,500 kilometres west of the Rift Valley (Chad). Nature 378, 273-275 (1995).

2. Brunet, M. et al. Australopithecus bahrelghazali, une nouvelle espèce d'Hominidé ancien de la région de Koro Toro (Tchad). C. R. Acad. Sci. Paris 322, 907-913 (1996).

3. Brunet, M. et al. A new hominid from the Upper Miocene of Chad, Central Africa. Nature 418, 145-151 (2002).
} 
4. Wolpoff, M., Senut, B., Pickford, M. \& Hawks, J. Sahelanthropus or 'Sahelpithecus'? Nature 419, 581-582 (2002)

5. Brunet, M. et al. Sahelanthropus or 'Sahelpithecus'? (Reply). Nature 419, 582 (2002).

6. Vignaud, P. et al. Geology and palaeontology of the Upper Miocene Toros-Menalla hominid locality, Djurab Desert, Northern Chad. Nature 418, 152-155 (2002).

. Brunet, M. et al. Tchad: un nouveau site à Hominidés Pliocène. C. R. Acad. Sci. Paris 324, 341-345 (1997).

8. Deino, A. L., Tauxe, L., Monaghan, M. \& Hill, A. $\mathrm{Ar}^{40} / \mathrm{Ar}^{39}$ geochronology and paleomagnetic stratigraphy of the Lukeino and lower Chemeron Formations at Tabarin and Kapcheberek, Tugen Hills, Kenya. J. Hum. Evol. 42, 117-140 (2002).

9. MacDougall, I. \& Feibel, C. in Lothagam the Dawn of Humanity in Eastern Africa (eds Leakey, M. G. \& Harris, J. M.) 43-64 (Columbia University Press, New York, 2003).

10. Haile-Selassie, Y., Suwa, G. \& White, T. Late Miocene teeth from Middle Awash, Ethiopia, and early hominid dental evolution. Science 303, 1503-1505 (2004)

11. Haile-Selassie, Y. Late Miocene hominids from the Middle Awash, Ethiopia. Nature 412, 178-181 (2001)

12. White, T. D., Suwa, G. \& Asfaw, B. Australopithecus ramidus, a new species of hominid from Aramis, Ethiopia. Nature 371, 306-312 (1994).

13. Wood, B. A., Abbott, S. A. \& Uyttershaut, H. Analysis of the dental morphology of Plio-Pleistocene hominids. IV. Mandibular postcanine root morphology. I. Anat. 156, 107-139 (1988).

14. Senut, B., Pickford, M., Gommery, D., Mein, P. \& Cheboi, K. First hominid from the Miocene (Lukeino Formation, Kenya). C. R. Acad. Sci. Paris 332, 137-144 (2001).

15. Zollikofer, C. P. E. et al. Virtual cranial reconstruction of Sahelanthropus tchadensis. Nature doi: $10.1038 /$ nature03397 (this issue).

Acknowledgements We thank the Chadian Authorities (Ministère de l'Éducation Nationale de l'Enseignement Supérieur et de la Recherche, Université de N'djaména, CNAR), the Ministère Français de l'Éducation Nationale (Faculté des Sciences, Université de Poitiers), the Ministère de la Recherche (CNRS: Département SDV \& ECLIPSE), the Ministère des Affaires Étrangères (DCSUR, Paris and SCAC, N'Djamena) to the Région Poitou-Charentes, the American School of Prehistoric Research, the RHOI (co-Principal Investigators F. C. Howell and T. D. White), the Armée Française, MAM and Epervier for logistical support; the scanner staff of the University Museum, the University of Tokyo (microCT scanning, G. Suwa); to the ESRF, Grenoble (W. G. Stirling, General Director, A. Bravin and C. Nemoz, ID 17); many colleagues and friends for their help, especially G. Suwa for enamel thickness measurements, P. Tafforeau for ESRF threedimensional scan reconstructions; T. D. White for discussions; all the other members of the Mission Paléoanthropologique Franco-Tchadienne (MPFT) who joined us for field missions; S. Riffaut and X. Valentin for technical support; and G. Florent and C. Noël for administrative guidance at the MPFT.

Competing interests statement The authors declare that they have no competing financia interests.

Correspondence and requests for materials should be addressed to M.B. (michel.brunet@univ-poitiers.fr). fracturing, displacement and plastic deformation. Here we present a detailed virtual reconstruction of the TM 266 cranium that corrects these distortions. The reconstruction confirms that $S$. tchadensis is a hominid and is not more closely related to the African great apes ${ }^{4,5}$. Analysis of the basicranium further indicates that $S$. tchadensis might have been an upright biped, suggesting that bipedalism was present in the earliest known hominids, and probably arose soon after the divergence of the chimpanzee and human lineages.

Primary distortion in TM 266-01-60-1 results from morphological discontinuities along major cracks between the left and right sides of the face, between the supraorbital torus and the zygomatics, between the left and right posterior cranial vault including the nuchal plane and basioccipital, and along a coronally oriented crack between left frontal and temporoparietal portions of the vault (Fig. 1; also see Fig. 1 in ref. 1). However, anatomical continuity is well preserved in the sagittal and parasagittal planes, particularly between the face, the neurocranium and the basicranium. Anatomical continuity in the basicranium extends from the basisphenoid to the nuchal plane and within each of the cranial units delimited by major cracks, as evident from matching fracture lines between adjacent parts. Plastic deformation resulting in left-right asymmetry is noticeable in the maxilla. The fossil is barely affected by expanding matrix distortion ${ }^{6}$, and no missing regions need to be estimated to reconstruct its original form.

A high-resolution computed tomography scan was used to create a digital representation of the TM 266 cranium that was disassembled along major cracks, cleaned of adhering matrix with the use of digital filtering, and then reconstructed virtually with two different established protocols (see Methods). The reconstruction, illustrated in Fig. 2, was evaluated with three independent tests. First, the face and neurobasicranial complex, which were reconstructed separately, fitted together at multiple points in an approximately coronal plane along the superior and lateral margins of the post-orbital region. Second, the reconstructed morphology was assessed a posteriori against an anatomical constraint not considered during the virtual reconstruction. In all mammals including primates, the posterior maxillary (PM) plane is approximately perpendicular relative to the neutral horizontal axis (NHA) of the orbits ${ }^{7}$. PM orientation was estimated by a plane that passes, in lateral projection, from the maxillary tuberosities through the pterygopalatine fossae ${ }^{8}$. In the TM 266 reconstruction, this plane is about $89^{\circ}$ relative to the NHA (estimated from the orbital margins and the partly preserved medial walls). As a third test, the TM 266 reconstruction was compared with three-dimensional shape variability in a comparative African ape/fossil hominid sample (see Methods). We performed a generalized least-squares superimposition ${ }^{9}$ of the symmetrized landmark configurations ${ }^{10}$ of all specimens and calculated the minimum form change necessary to transform the TM 266 reconstruction to the closest possible hypothetical Pan and Gorilla cranial forms with the use of the $99 \%$ probability density borders as a minimum-distance criterion (Fig. 3). Figure $3 a-c$ shows this procedure for the first three PCs, which account for more than $58 \%$ of the total shape variability. To account for allometric shape effects, all shape PCs were regressed against centroid size to obtain a common allometric shape score ${ }^{11}$ (Fig. 3d). The isolated fragments of the TM 266 cranium were then positioned to fit the calculated three-dimensional landmark configurations of the closest-possible Pan and Gorilla shapes (Fig. 3e). The resulting 'Pan-like' and 'Gorilla-like' morphologies are anatomically infeasible, involving overlap between neurocranial fragments and disruption of anatomical continuity between neighbouring facial fragments. Although the cranial morphology of TM 266-0160-1 cannot be reconstructed to fall within the size-shape

Previous research in Chad at the Toros-Menalla 266 fossiliferous locality (about 7 million years old) uncovered a nearly complete cranium (TM 266-01-60-1), three mandibular fragments and several isolated teeth attributed to Sahelanthropus tchadensis $^{1-3}$. Of this material, the cranium is especially important for testing hypotheses about the systematics and behavioural characteristics of this species, but is partly distorted from 